\title{
Implementation of a Novel Malaria Management Strategy Based on Self-testing and Self-treatment in Remote Areas in the Amazon (Malakit): Confronting a- priori Assumptions With Reality
}

\section{Muriel Suzanne GALINDO ( $\nabla$ muriel.galindo@hotmail.fr)}

Institut national de la santé et de la recherche médicale: INSERM https://orcid.org/0000-0002-1815-4820

Yann Lambert

Centre Hospitalier de Cayenne: Centre Hospitalier Andree Rosemon

Louise Mutricy

Centre Hospitalier de Cayenne: Centre Hospitalier Andree Rosemon

\section{Laure Garancher}

The Ink Link

Jane Bordalo Miller

DPAC Fronteira

José Hermenegildo Gomes

DPAC Fronteira

\section{Alice Sanna}

Centre Hospitalier de Cayenne: Centre Hospitalier Andree Rosemon

\section{Cassio Peterka}

Ministério da Saúde: Ministerio da Saude

\section{Hedley Cairo}

Ministry of Health

Helene Hiwat

Ministry of Health

\section{Antoine Adenis}

Centre Hospitalier de Cayenne: Centre Hospitalier Andree Rosemon

Mathieu Nacher

Centre Hospitalier de Cayenne: Centre Hospitalier Andree Rosemon

Martha Cecilia Suárez-Mutis

Fundação Oswaldo Cruz: Fundacao Oswaldo Cruz

\section{Stephen Vreden}

Stichting Wetenschappelijk Onderzoek Suriname

\section{Maylis Douine}

Centre Hospitalier de Cayenne: Centre Hospitalier Andree Rosemon 
Keywords: border malaria, mining population, remote health, process evaluation, implementation outcomes Posted Date: August 5th, 2021

DOl: https://doi.org/10.21203/rs.3.rs-764314/v1

License: (a) (i) This work is licensed under a Creative Commons Attribution 4.0 International License. Read Full License

Version of Record: A version of this preprint was published at BMC Public Health on April 15th, 2022. See the published version at https://doi.org/10.1186/s12889-022-12801-0. 


\section{Abstract}

Background: An innovative strategy to combat malaria was tested with a methodology adapted to a complex setting in the Amazon region and a hard-to-reach, mobile population. The intervention strategy tested was the distribution, after training, of self-diagnosis and self-treatment kits to gold miners who cross the Surinamese and Brazilian borders with French Guiana to work illegally in the remote mining sites in the forest of this French overseas territory. The main evaluation criterion was the reported behavioral change in case of malaria symptoms, measured by pre- and post-intervention surveys.

Method: This article informs on the quality of delivery, content adherence and facilitation strategies, exposure to the intervention, participants responsiveness and unintended consequences. The information sources are the post-intervention survey, a short data collection carried out in a very isolated gold mining site, continuous data collection during the intervention, observations made during supervision visits, and in-depth feedback from the project players.

Results and Discussion: As expected, being part of or close to the study community was an essential condition for facilitators to overcome the usual wariness of this population. Regarding the content of the delivered messages, the main issue with facilitators was the excess of information rather than the omission of information but was corrected over time. The content of the intervention was overall in line with what was planned. With an estimation of one third of the population reached, the exposure was satisfactory considering the challenging context, but improvable by increasing ad hoc offsite distribution according to the needs. Participants' responsiveness was the main strength of the intervention but could be enhanced by reducing the duration of the process to get a kit, which can be disincentive in some places. The expected decrease in malaria became a source of reduced interest in the kit. Expanding the remit of facilitators may be a suitable response. Better integration of the articulation with the existing malaria management services is recommended for sustainability.

Conclusion: These findings provide valuable implementation outcomes to complement the evaluation outcomes for assessing the relevance of the strategy and information useful to sustain and transfer it in analogous contexts.

Trial registration: ClinicalTrials.gov

Registration number: NCT03695770

Date of registration: 10/02/2018 "Retrospectively registered"

\section{Contributions To The Literature}

- In French Guiana, the only European territory in South America, providing malaria diagnosis and treatment to a mobile and illegal gold mining population using recommended strategies is unfeasible due to regulatory, geographic and security constraints.

- Testing an intervention consisting in providing malaria self-management kits to lay people by non-health professionals at border resting sites, along with appropriate training and resources, is unprecedented.

- These findings complement the evaluation results by presenting what was actually implemented, adherence to what was planned, quality of delivery, exposure to the intervention, participant responsiveness, and 
unintended consequences.

\section{Background}

Ineffective programs can be implemented well while useful programs can be badly implemented $(1,2)$. Knowing the degree to which an intervention that was implemented corresponds to the intervention initially designed may be very helpful when assessing the sustainability, applicability or transferability of a strategy $(3,4)$.

In any kind of research, the experimental design is considered as the most rigorous methodology to ensure the highest level of evidence (5-7). In some contexts however, random allocation of individuals or clusters is not feasible: this may actually be an opportunity in disguise. Indeed, the quest for the gold standard methods may overshadow the relevance of a more pragmatic design, and some of its advantages, such as transferability $(3,8,9)$. Such circumstances are met in the Guiana Shield located in the Amazon region, more specifically in the French overseas territory of French Guiana, neighbored by Suriname and the Brazilian State of Amapá. The mining potential of the area inherited from its rich geological history attracts a highly mobile and disperse community mainly coming from the poorest regions of Brazil. The living and working conditions - long working days, stagnant water due to alluvial gold mining, etc. - of these gold miners are conducive to malaria, which is endemic in the region (10-13). Identified as a reservoir and a barrier to elimination of the disease, this neglected population was addressed by an innovative research project called Malakit(14-16). This international collaborative project aimed at evaluating the preventive distribution of malaria self-management kits to gold miners, on resting sites at the borders, with information and training, to be used when isolated in the forest $(15,17)$. The great geographical constraints and the cross-border context involving a sensitive undocumented migrant population raised serious methodological challenges (18). A before-after study design was set up using measurable, realistic and comparable variables and specific indicators with different modes of collection. The main evaluation criterion was based on the comparison between the estimated proportion of reported good practice of diagnosis and treatment, before and after the intervention using cross-sectional surveys $(15,17)$. To complete these indicators, continuous and longitudinal data collection was implemented to assess the correct use of the kit. Between April 2018 and March 2020, 4,766 kits were distributed to 3,733 participants, among whom 631 returned to a distribution site to answer questions about their experience, 223 of whom used at least one malakit (19). This ongoing evaluation was complemented by an independent qualitative study aiming at exploring:1) the opinion, perception and responsiveness of participants, facilitators and also key actors who are community members not eligible to the intervention, 2) levers and barriers to the use of the malakit, 3) facilitators' role and 4) contextual elements (20).

Borders and migrations are challenging for health interventions, notably for malaria. Border malaria has long been a problem, notably in South East Asia (border between Myanmar and Thailand and between Cambodia and Thailand, for example) where antimalarial resistance has repeatedly emerged in a particular mix of local circumstances $(21-23)$. Throughout the history of malaria programs, there have been great efforts to target this complex transnational context (23-26). Furthermore, certain activities, often illegal (guerrilla warfare, logging, mining), have been important drivers of malaria epidemiology. In South America (Venezuela, Colombia for instance) malaria has been linked with mining or more largely with extractive activities $(10,27-30)$. The malaria problem on the Guiana shield is thus specific but related to situations found elsewhere in the world. 
The communication of results does not always take into account how interventions were implemented and how context affects implementation and outcomes $(4,31)$. The objective of the article is to detail the solutions that have been implemented locally, and how the planned intervention unfolded in the reality of a challenging context in order to extract applicability and transferability to other contexts with their set of interventional constraints $(3,32)$.

\section{Methods}

The context, the content of the intervention, the actors and the stages of development have been described in previous articles $(15,17)$. Defining properly the research type of a study is useful since clarity may avoid duplications, funding inefficiencies and difficulties in seeking and understanding information by the end-users of research evidence (33). The Malakit project, by developing an unprecedented approach to malaria management, can be classified as intervention research. At design phase, its evaluation aimed at determining intervention effectiveness with health and behavioral outcomes. However, intervention and implementation research do not always have clear boundaries and may closely overlap (33). Indeed, Malakit could also be considered as an implementation strategy for the "Test and Treat" intervention with Rapid Diagnostic Tests (RDTs) and Artemisininbased combination therapy (ACTs). In support of this, several implementation research outcomes were also included in the evaluation. Therefore, the term of Type 2 effectiveness-implementation hybrid trial can be attributed to the Malakit study (34-36). This article presents elements of implementation fidelity targeted according to Carroll et al.'s conceptual framework, and unintended consequences and aspects of context as defined by the Medical Research Council (MRC) framework $(4,37)$. Adherence to content was analyzed based on observations during regular supervision and monitoring visits. Dose, also called exposure, was estimated or quantified through a post-intervention survey on resting sites, onsite data collection after one year of implementation in a remote and hard-to-reach clandestine gold mining site (Repentir mission), and continuous monitoring data (Malakit intervention) (38). Participants responsiveness explored by the external qualitative study mentioned earlier are further documented in this article (20). More specifically, opinions from gold miners were collected quantitatively during the post-intervention survey and Repentir mission. Facilitators' opinions and perceptions were self-recorded through videos in which facilitators responded to a list of questions written by sponsor team (20). Quality of delivery and facilitation strategies are evoked as part of adherence to content analysis.

Information collected from informal in-depth debriefings all along the implementation were also useful to analyze these indicators.

\section{Key components of the intervention}

The "logic model of the Malakit intervention" is described in Fig. 1. The principle of the intervention was the handing over of a self-diagnostic and self-treatment kits at borderer resting sites to persons working illegally on gold mining sites in French Guiana, to be used inside the forest, far from the health care system (Fig. 2). This "malakit" included three diagnostic tests, a full artemisinin-based combination therapy (ACT) course, a single dose of primaquine, and paracetamol (15). Illustrated instructions were printed directly on the plastic pouch of the kit (Fig. 3). The role of facilitators was to recruit, provide information and training with specific tools, and decide if the participant fulfills the conditions to get a malakit i.e. meets the eligibility criteria: performs and interprets a self-test under supervision and understands when and how to take the medication of the kit. Facilitators were 
also in charge of collecting longitudinal data at inclusion visit and subsequent follow-up visits of participants, when they come back to get a new kit or kit replenishment (Fig. 2).

The main objective of the project was to increase the use of an appropriate and complete malaria treatment against $P$. falciparum, the most prevalent species at the beginning of the study among garimpeiros (Portuguese term for small-scale and/or illegal gold miners) (14), with ACT, also effective against $P$. vivax malaria attacks (but not relapses), promptly after the onset of the disease $(14,15,39-41)$.

\section{Results}

The total length of the interventional research was 24 months in Suriname and 18 months in Brazil, between April 2018 and March 2020. Seventeen supervisory missions were held in Suriname and 15 in Brazil. In both countries, the first mission was held within one month after the launch, and the last one took place one month before the end of the study, i.e. until it became impossible to travel due to the closure of borders in the context of the Covid19 pandemic. In Brazil, 21 inclusion visits and 10 follow-up visits were the objects of observation. In Suriname 15 inclusion visits and four follow-up visits were the objects of supervision reports, although more were actually observed.

\section{Adherence to protocol}

Additional file 1 details the adherence to content, adaptations and facilitation strategies of the key activities of Malakit i.e. inclusion, training, kit distribution and replenishment or re-distribution.

During rollout of the intervention on the distribution sites, some planned components of the intervention had to be abandoned during the development phase of the project, even before the setting up. One example is that of the places identified to be training and distribution points. Those were the most important resting sites on the two border rivers, on the Surinamese and Brazilian side but some were also located on the French Guianese side. However, implementing the intervention on the French territory was finally not included in the protocol. Higher costs mainly due to the high price of the ACT in the European Union, and poor added value in terms of coverage of the intervention, have led to the abandoning of attempts to overcome regulatory constraints, such as the absence of marketing authorization for the use of the Carestart ${ }^{\mathrm{TM}}$ test on oneself, or the fact that the targeted persons do not have French health insurance.). Another example was the opening of the five distribution sites, initially planned over a short period of time to allow a massive distribution of kits and thus drastically reduce their value on the black market, thereby discouraging trade by participants (42). In practice, the intervention was progressively scaled up due to logistical and regulatory constraints. The bright side of this sequential initiation was an opportunity to capitalize and learn from experience, and eventually to improve the implementation which in the end did not lead to massive black market sales according to Malakit data and informal sources of information. The intervention had to adapt to different contexts depending on the location and features of the distribution sites (see Table 1). 
Table 1

Characteristics of distribution sites of the Malakit intervention in Suriname and Brazil (April 2018-March 2020)

\begin{tabular}{|c|c|c|c|c|c|c|}
\hline $\begin{array}{l}\text { Name of } \\
\text { distribution } \\
\text { site }\end{array}$ & $\begin{array}{l}\text { Number of } \\
\text { full-time } \\
\text { facilitators }\end{array}$ & $\begin{array}{l}\text { Turn over } \\
\text { of } \\
\text { facilitators }\end{array}$ & Premise type & Location & $\begin{array}{l}\text { Distance } \\
\text { for place } \\
\text { of referral }\end{array}$ & Characteristics \\
\hline \multicolumn{7}{|l|}{ Suriname } \\
\hline Albina & 1,5 & No & $\begin{array}{l}\text { Small } \\
\text { prefabricated. } \\
\\
\text { Already a } \\
\text { "malaria } \\
\text { clinic" before } \\
\text { the project } \\
\text { start. }\end{array}$ & $\begin{array}{l}\text { Logistic base, } \\
\text { near shops } \\
\text { and resting } \\
\text { place gold } \\
\text { miners }\end{array}$ & $\begin{array}{l}\text { In situ, a } \\
\text { facilitator } \\
\text { is also a } \\
\text { malaria } \\
\text { "test an } \\
\text { treat" } \\
\text { worker } \\
\text { (MSD) }\end{array}$ & $\begin{array}{l}\text { Most of gold } \\
\text { miners are there } \\
\text { in transit for a } \\
\text { very short } \\
\text { period of time. } \\
\text { First mining } \\
\text { sites are very } \\
\text { close. }\end{array}$ \\
\hline $\begin{array}{l}\text { Antonio do } \\
\text { Brinco }\end{array}$ & 2 & No & $\begin{array}{l}\text { No fixed } \\
\text { facility, }\end{array}$ & $\begin{array}{l}\text { Mobile } \\
\text { facilitators in } \\
\text { a gold miners } \\
\text { village, or in a } \\
\text { church (when } \\
\text { the level of } \\
\text { water does not } \\
\text { allow walking) }\end{array}$ & $\begin{array}{l}\text { Malaria } \\
\text { clinic with } \\
\text { a MSD } \\
\text { within the } \\
\text { village, but } \\
\text { not used } \\
\text { by the } \\
\text { facilitators }\end{array}$ & $\begin{array}{l}\text { Most of gold } \\
\text { miners live and } \\
\text { stay there for a } \\
\text { rather long } \\
\text { period of time. } \\
\text { First mining } \\
\text { sites are very } \\
\text { close. }\end{array}$ \\
\hline Paramaribo & $\begin{array}{l}1 \text { (initially } \\
6 \text { part- } \\
\text { time) }\end{array}$ & Yes & $\begin{array}{l}\text { Office in a } \\
\text { hotel }\end{array}$ & $\begin{array}{l}\text { Brazilian } \\
\text { quarter in the } \\
\text { capital of } \\
\text { Suriname, } \\
\text { hotel } \\
\text { frequented by } \\
\text { gold miners. } \\
\text { The facilitator } \\
\text { also works in } \\
\text { the hotel. }\end{array}$ & $\begin{array}{l}\text { Tropclinic } \\
\text { is } 5 \\
\text { minutes } \\
\text { away by } \\
\text { taxi. }\end{array}$ & $\begin{array}{l}\text { Short stay of } \\
\text { the majority of } \\
\text { gold miners. } \\
\text { Passage of gold } \\
\text { miners working } \\
\text { specifically in } \\
\text { French Guiana } \\
\text { is less frequent. }\end{array}$ \\
\hline
\end{tabular}

Brazil

$\begin{array}{lll}\text { Oiapoque } 2 & \text { Yes } & \begin{array}{l}\text { Fixed office in } \\ \text { a flat }\end{array}\end{array}$

Small town, within the goldminers' quarter

Health
centers
and a
hospital in
the town
but not in
the
quarter.

Departure place for goldmining sites, but no sites in the vicinity. Many gold miners have a permanent accommodation in the town.

$\begin{array}{llll}\text { Ilha Bela } & 2 & \text { Yes } & \text { Shack }\end{array}$

$\begin{array}{ll}\text { Shack } & \text { Within a small } \\ \text { spontaneously } \\ \text { founded } \\ \text { village (not } \\ \text { recognized } \\ \text { officially) of } \\ \text { gold miners }\end{array}$

\begin{tabular}{|c|c|}
\hline $\begin{array}{l}\text { No } \\
\text { malaria } \\
\text { care in }\end{array}$ & $\begin{array}{l}\text { Isolated } \\
\text { villages. }\end{array}$ \\
\hline $\begin{array}{l}\text { care in } \\
\text { situ. }\end{array}$ & First mining \\
\hline $\begin{array}{l}\text { Oiapoque } \\
\text { is the first } \\
\text { referral }\end{array}$ & $\begin{array}{l}\text { sites are very } \\
\text { close. }\end{array}$ \\
\hline $\begin{array}{l}\text { place at } \\
4-5 \text { hours } \\
\text { by boat. }\end{array}$ & $\begin{array}{l}\text { Facilitators are } \\
\text { based in Ilha } \\
\text { Bela and go to }\end{array}$ \\
\hline
\end{tabular}




\begin{tabular}{|lllllll|}
\hline $\begin{array}{l}\text { Name of } \\
\text { distribution } \\
\text { site }\end{array}$ & $\begin{array}{l}\text { Number of } \\
\text { full-time } \\
\text { facilitators }\end{array}$ & $\begin{array}{l}\text { Turn over } \\
\text { of } \\
\text { facilitators }\end{array}$ & Premise type & Location & $\begin{array}{l}\text { Distance } \\
\text { for place } \\
\text { of referral }\end{array}$ & Characteristics \\
\hline Vila Brasil & & & Health center & $\begin{array}{l}\text { Village at } 30 \\
\text { minutes from } \\
\text { llha Bela }\end{array}$ & $\begin{array}{l}\text { Vila Brasil twice } \\
\text { a week. }\end{array}$ \\
\cline { 3 - 4 } & & & & \\
\hline
\end{tabular}

\section{Human resources and coordination}

Human resources are the most important elements in most community-based approaches. The workers in this project were called "facilitators" ("mediadores" in Portuguese, "médiateurs" in French). They may not be named "community health workers (CHW)" in the sense that they were not active gold miners, were not chosen by the community and were more accountable for their employer than for the community (43). Nonetheless, belonging to or being close to the community of garimpeiros and being fluent in Portuguese, were fundamental. Having sufficient literacy skills for tablet and smartphone use was desirable competencies. Partners in both countries reported that recruitment was difficult due to lack of eligible candidates. Solutions to address this problem are not yet identified. Two facilitators were assigned to each of the four border sites (see Fig. 4). In Paramaribo, tasks related to Malakit were added to the duties of the National Malaria Control Program (NMCP) staff, but after an obvious failure in the quality of service, the strategy was reviewed and a full-time facilitator was assigned to this site (see Additional file 1). Some persons recruited were not native Portuguese speakers despite the initial recommendations. Three of them reported a wary attitude at initial contact from the gold miners, attributed to their accent betraying the fact that they were not Brazilian. Most of facilitators had little or no knowledge of malaria and had various occupations, such as pastor or boatman. Facilitators without medical background revealed a better ability to adapt the discourse to the needs of the study population. High turnover on the Brazilian side was a constraint to smooth capacity building. One of the explanations was that a person was detrimental to the functioning of the local team. The late payment of wages due to the international fund transfer delays, and the uncertainty regarding the end date of the pilot phase related to a start-up delay caused by presidential elections, may also have contributed to a feeling of precariousness. Three facilitators reported that what they liked most about their work was acquiring new knowledge. Continuous capacity building is probably crucial to maintain human resources and sustain their motivation. Furthermore, the feeling of being useful and part of an innovative project which they believed in was an important incentive shared by the vast majority (44).

One principal investigator located in Rio de Janeiro and one coordinator in Oiapoque were responsible for the Brazilian sites. A single person was both coordinator and principal investigator in Suriname. However, these assignments were in addition to their usual work. Due to the distance between the sponsor team in Cayenne and the distribution sites, the presence of a supervisor hierarchically above facilitators in each country was decided, in addition to the regular visits of the sponsor team and the continuous monitoring of data collected by facilitators (see Fig. 4). In the long run, direct interaction between the sponsor team and facilitators on the field on both river borders proved to be more convenient. Indeed, except on two sites, the distance was also an issue for frequent onsite supervising visits. Lack of availability due to lack of time on one side and difficulties to recruit a permanent supervisor on the other side was a reason for poor ongoing training. Nonetheless, the ambiguity of the supervision role of the sponsor team in Cayenne without hierarchical relations was sometimes confusing for facilitators. 
Facilitators were provided with "field reports" to counteract distance issues. The purpose was to improve and homogenize practices by capitalizing on field experiences, reminding important points, and formalizing some guidelines. This information was provided digitally on an instant messaging group and on paper. Despite efforts to make the instructions synthetic and palatable with the addition of diagrams and pictures, facilitators showed variable interest in these reports. One-to-one direct debriefings, either in person or via instant messaging, had better impact. Oral culture seemed to prevail over written culture among facilitators.

\section{Content and quality delivery}

All tools created for the training were systematically used, except one poster illustrating the effect of the ACT on the malaria over time and the mechanism of resistance (Fig. 5), which was forsaken by some facilitators who found it redundant with the illustration on the kit about the treatment (Fig. 3).

Sometimes, less may be more. The shortcoming encountered, mainly at the beginning, was the surplus of information, or inaccurate information rather than the lack of information given by facilitators to participants. Adding too much detail may dilute the important information, or make it confusing, and eventually become detrimental to the training. For example, one facilitator described the drug primaquine included in the kit as abortifacient, when explaining that it should not be taken by pregnant women, which can lead to misuse for that very purpose. While speaking about risk situations, instead of only explaining the danger of Coartem ${ }^{\circledR}$ in case of heart problems, a facilitator mentioned the risk also for Artecom ${ }^{\circledR}$, the main antimalarial drug found on the black market. This may confuse the message about avoiding under-the-counter medications. As time went by, the talk was well mastered. The facilitators confirmed that they adapted the time spent explaining, the stress on specific messages, the number of repetitions, and the vocabulary according to the audience and its availability, as the training was highly interactive.

\section{Exposure to the intervention and participants responsiveness Intervention availability for the study population}

Despite a delay in implementation on the Brazilian side due to regulatory issues related to the 2018 context of presidential election, the project was not shortened thanks to the obtaining of funds for a six-month extension. Furthermore, a continuous presence of the facilitators on distribution sites was ensured, with the exception of end-of-year holidays.

While the location of the distribution sites was determined at the beginning of the study, the protocol included the possibility to adapt the strategy according to the mobility of the study population. These ad hoc relocations of the intervention to additional resting sites proved to be very effective in reaching the study population but could not be repeated as often as necessary due to insufficient funding and human resources.

Several contextual factors can influence the mobility and thus the frequentation of resting sites. The following are the main ones identified: 1) The French police operations on mining sites in French Guiana, and of the presence of Brazilian army on the Brazilian border; 2) Seasons and periods of the year (for example more movements during end-year holidays); 3) Gold mining activity depending on the location of gold seams and 'rush' following rumors of new discoveries (in Portuguese, fofoca), and indirectly the presence of armed gangs (facções); 4) Role on gold mines, mobile activity (e.g travelling vendors, transport providers and porters) versus non-mobile activity (e.g. goldminers, shop owners, machine owners). 


\section{Malakit awareness and participation}

From post-intervention surveys sampling gold miners at resting sites - one at the Suriname border and the other at the Brazilian border - the estimated coverage of Malakit participation among persons frequenting resting sites was $29.7 \%(95 \% \mathrm{Cl}$ [25.7-33.7], $n=147 / 493)$ in December 2019 (19). This measure probably overestimates overall coverage because people who participated in the post-intervention survey are likely to take better care of their health and thus have a higher probability of also participating in the Malakit intervention, and because it does not take into account gold miners who stay in the forest for very long periods. However, data collected in a very remote and isolated site one year after the start of distributions (Repentir mission in June 2019) showed satisfactory penetration of the intervention. The representativeness of this sample was low since only 25 people were interviewed with a high proportion of women ( $64 \%$ vs. $34 \%$ among Malakit participants). Nonetheless, $28 \%$ $(95 \% \mathrm{Cl}[9.1-46.7])$ of the persons met were included in the Malakit study. Finally, for a population of approximately 10,000 gold miners, reaching more than 3,700 people in two years is satisfactory given the challenging context.

Results from both the post-intervention survey and Repentir mission showed that around two thirds had heard about the project (respectively $64.8 \%, 95 \% \mathrm{CI}[60.6-69.0]$ and $60 \%, 95 \% \mathrm{Cl}[39.3-80.6]$ ) and that about half of those who knew about it were participating (respectively $46.1 \%, 95 \% \mathrm{Cl}[40.6-51.6]$ and $47 \%, 95 \% \mathrm{Cl}[18.1-75.3]$ ). The findings of the qualitative study revealed a good knowledge of Malakit but a probable heterogeneity of the project awareness from one site to another (20).

\section{Opinion on Malakit}

The strong acceptance and enthusiasm of project facilitators and participants that emerged from the qualitative study was confirmed by the findings from the post intervention survey and Repentir mission (20). From the former source, $81.5 \%(95 \% \mathrm{Cl}[77.3-85.8])$ of the 320 respondents acknowledged either the importance of the strategy for the population or its public health significance. Only four people expressed a negative opinion either because of the perception that the medication of the kit was not effective, the lack of usefulness due to the absence of malaria, or the requirement to prick oneself. Repentir mission revealed that 12 persons out of 15 who knew about the project had very good opinion of Malakit. Only one person had a bad opinion and also thought that Coartem ${ }^{\circledR}$ was ineffective.

"It is useful because we can know what disease it is and which treatment to use."

"It is interesting and useful, my daughter-in-law was able to treat herself"

"It is good", one of the positive pieces of feedback from colleagues that had used it, "good project".

\section{Barriers to participation}

The motives for not participating among persons who had heard about the project were documented for 135 people from the post intervention survey (Table 2). Not having the opportunity to go to a distribution site was the main reason $(40 / 135,29.6 \%)$. Lack of access to Malakit sites primarily due to travel cost and time but also sometimes related to the fear of enforcement authorities, was also the main obstacle identified in the qualitative study (20). According to this same source, gold miners acknowledged that time for the training and questionnaire can be disincentive. Facilitators also stressed on the importance of making the process before handing the kit 
quick and when asked what could be improved, three of them mentioned the shortening of visits. One suggested to reduce the training part with more videos and one proposed to remove questions to shorten follow-up visits $(20,44)$. The inclusion process lasted between 30 and 45 minutes but the metadata analysis of monitoring questionnaires revealed that the median time spent on electronic data capture was five minutes, after debriefing with the participant, for both types of visits combined (42). Reasons for refusing to be part of the study were collected by Malakit facilitators among people who were approached, in other terms who had the opportunity to go to a distribution site. The data are not exhaustive, come mainly from a specific site and mainly from persons who had started the training (Table 2). Lack of time is once again the main barrier that emerged.

Table 2

Reasons for not participating in the Malakit study (Suriname and Brazil)

\begin{tabular}{|c|c|c|c|}
\hline \multirow[t]{4}{*}{ Reason } & \multirow{4}{*}{ 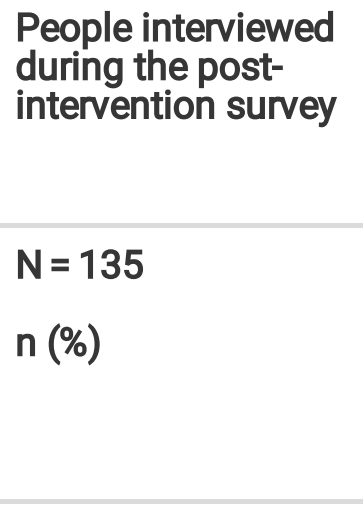 } & \multicolumn{2}{|c|}{$\begin{array}{l}\text { People approached by } \\
\text { facilitators during Malakit } \\
\text { intervention } \\
\text { (several possible answers) }\end{array}$} \\
\hline & & Total & $\begin{array}{l}\text { People who had } \\
\text { started the training }\end{array}$ \\
\hline & & $\begin{array}{l}N= \\
250\end{array}$ & $N=140$ \\
\hline & & $\mathrm{n}(\%)$ & $\mathrm{n}(\%)$ \\
\hline $\begin{array}{l}\text { Not having had the opportunity to go to a } \\
\text { distribution site }\end{array}$ & $40(29.6)$ & $\mathrm{i}$ & $\mathrm{i}$ \\
\hline Unawareness of where to get a kit & $7(5.2)$ & $\mathrm{i}$ & $\mathrm{i}$ \\
\hline Having obtained a kit by another mean & $6(4.4)$ & $\mathrm{i}$ & $\mathrm{i}$ \\
\hline Absence of facilitators at the inclusion site & $3(2.2)$ & $\mathrm{i}$ & $\mathrm{i}$ \\
\hline Lack of time & $30(22.2)$ & $\begin{array}{l}144 \\
(57.6)\end{array}$ & $58(41.4)$ \\
\hline $\begin{array}{l}\text { Not interested in the Malakit project or lack of } \\
\text { recognition of utility due to perceived absence of } \\
\text { malaria }\end{array}$ & $35(25.9)$ & $\begin{array}{l}86 \\
(34.4)\end{array}$ & $33(23.6)$ \\
\hline Fear of needles & $1(0.7)$ & $\begin{array}{l}77 \\
(30.8)\end{array}$ & $66(47.1 \%)$ \\
\hline Unable to perform the RDT & ii & $\begin{array}{l}7 \\
(2.8)\end{array}$ & $7(5 \%)$ \\
\hline Refusal to share personal information & $2(1.5)$ & $\begin{array}{l}3 \\
(1.2)\end{array}$ & $2(1.4 \%)$ \\
\hline
\end{tabular}


The ability and willingness of potential participants to spend their time for Malakit training was more or less pregnant depending on the distribution location (see Table 1). In distribution sites where gold miners were just passing through before final destination (e.g., Albina) and/or where the departure by boat to the gold mining sites could be sudden and thus where gold miners were on the lookout (e.g., Vila Brasil), the time required for inclusion was a barrier, obtaining a malakit not being a priority. On the contrary, participants living at the resting site (Antonio do Brinco, Ilha Bela, Oiapoque) with no "competing activity" showed a much greater engagement in the intervention. Facilitators also reported better availability of participants on transient distribution points, during punctual missions.

Overall the fear of pricking oneself was occasional and some facilitators reported efficacious strategies to overcome this (see Additional file 1 and Table 2) (20). All the sources of information revealed that the inability to perform a self-test - excluding the fear of needles - and the reluctance to share personal data, - which were anticipated as potential barriers - were anecdotal. Facilitators confirmed that distrust was generally overcome and tended to decrease over the course of the project (20).

\section{Unexpected mechanisms and consequences}

\section{Influence of the research context}

Measurement may disturb the object measured. Although the degree of pragmatism is high on the pragmaticexplanatory continuum, the intervention was not implemented in fully "real-world" settings (9).

For example, the instruction given to facilitators not to judge participants misusing kits, like sharing kits, in order to encourage participants to tell the truth about practices may have led to a feeling from the participants that the sharing of the kit was acceptable. Moreover, the continuous and longitudinal collection of data carried out by the facilitators as part of a research project was more extensive than it would be for monitoring a public health intervention. Despite efforts to limit the number of questions and to avoid sensitive questions (e.g. questions on past whereabouts only, not on future destinations), the questionnaires may have been a source of suspicion for a community constantly on guard due to their illegal and clandestine status. Conversely, the multitude of partners from different countries (45) and the logos of which were displayed on easels and facilitators' vests, were a source of trust from the participants.

\section{Diagnosis discrepancies}

The difference of diagnostic method between Malakit; i.e. CareStart ${ }^{\mathrm{TM}}$ Malaria (Pan) and those provided at malaria clinic in Suriname, i.e. SD BIOLINE Malaria Antigen P.f/P.f/P.v® and microscopy, and Brazil, i.e. microscopy, sometimes led to divergent results. Because of the large number of persons tested, mostly asymptomatic, the frequency of such discordant diagnoses seemed high. An investigation using PCR as a gold standard found a false-positive proportion of $1.72 \%$, consistent with an expected false positive rate of $2.4 \%$ for a reported specificity of $97.6 \%$ and in a low prevalence setting, and a Positive Predictive Value of $40 \%$, consistent with the low PCR prevalence of 5.3\% measured during the post-intervention survey (19). Routine diagnosis was performed on Malakit participants only in case of symptoms or positive Malakit RDT on the Surinamese side and systematically on the Brazilian side. Despite an agreed common procedure between concerned stakeholders to address this problem, confusion among participants and decreased confidence in the Malakit RDT or in routine care were observed anecdotally. Moreover, the success of the intervention may have competed with the malaria 
routine care despite the complementarity of the two. A feeling of competition has been expressed by some healthcare workers, which was then dissipated with improvements in the communication.

\section{Risk related to the kit value}

The relatively high market value of the kit itself (more than two grams of gold i.e. about 50 USD according to gold miners'testimony) represented several risks. Despite close verification of stock flows, the discontinuous presence of supervisors on the field did not allow guaranteeing the absence of kits resale by facilitators.

\section{Epidemiological evolution}

During the project period, the incidence of malaria decreased at the gold mining sites and in the region. Preliminary modeling work estimated that the intervention itself helped avert $43 \%$ of the new malaria cases predicted in the absence of Malakit between April 2018 and March 2020 (19). This diminution can lead to the perception that malaria does not exist anymore and then to a diminished interest in the malakit. Towards the end of the project, facilitators of one particular site reported several cases of people not feeling concerned in the kit, because they considered malaria not to be present on their worksite anymore.

\section{Discussion}

Feedback from players who were engaged in the protocol (intervention design and evaluation) and tools development, training and close field supervision can constitute valuable information to complete "impact results".

The distinction of the "core components" and the adaptable elements related to an intervention can only be discerned through practice and mispractice over time as the intervention is more widely deployed and replicated in other contexts, as explained in the Consolidated Framework of Implementation Research (46). As an innovative strategy, several choices and adaptations were made during the implementation itself. Thus, the objective of this article was not to create fidelity measures to assess an evidence-based intervention but to capitalize on this unprecedented field experiment to contribute to future process evaluation or implementation research on the strategy. Workshop bringing together all facilitators and supervisors animated by an external assessor was planned in April 2020 but was cancelled due to the COVID-19 pandemic. While the main defect of the present assessment is the absence of quantitative indicators for content adherence, the main strength is the regularity of missions throughout the project and not only at specific periods, and in-depth feedback from the players.

Anyway, it is possible to affirm from observation data that the content of the messages and the way to transmit them were satisfactorily conforming to what was planned even if rectifications were necessary at the beginning. Dane and Schneider suggest (47) that lack of confidence, experience, as well as not being professional - i.e. paraprofessional or lay persons - were predictors of poor program integrity in preventive interventions research. On the contrary, in a study assessing the fidelity of implementation of malaria care for children by $\mathrm{CHWs}$ in Nigeria, adherence to the diagnostic, treatment and counseling protocol by CHWs was found to be equal or higher to that of the medical staff who served as gold-standard comparators, and not related to age, level of education or primary occupation (48). In the Malakit intervention, previous experience in health care or health mediation did not seem to be an asset - also because compared to other interventions no clinical evaluation was performed and excess of confidence was rather a barrier to compliance with what was planned, to the point of having to replace facilitators (see Additional file 1, "Terms and conditions to be included"). This is consistent with WHO's 
finding that $\mathrm{CHWs}$ may be men or women, young or old, literate or illiterate, as long as they blend into the culture of the community and ensure their acceptance (43). The geographical distance issues identified here as a main constraint in the implementation and monitoring, may be encountered in other contexts involving several countries and should be addressed. Field supervision and refresher trainings, very time-consuming when two days are needed to go to one place, should be assigned to someone dedicated to these tasks only; this person should actively collaborate to the elaboration and design of the training contents and data collection tools with the principal investigators. The development of refresher training tools for facilitators with a participatory approach - as used for participants training tools - to adapt to their literacy and needs, could also alleviate distance issues. Constant and long-term efforts to maintain quality are essential to adapt to evolving contexts, including beyond scale-up. Indeed, while resources allocated for research are sufficient to ensure integrity, for example through continuous in-person and distance supervision, decrease in fidelity is more likely when interventions are adopted and sustained (47). Indeed, although ongoing training in any form, including supportive supervision, is a recommended practice, some negative outcomes associated to it have been reported and linked with dissatisfaction (49). Facilitators did not express such discontent despite all opportunities to do so. Using mobile technologies in particular was rather well accepted (42). In low and middle income countries, it is increasingly seen as an opportunity to better train and improve performance of workers remotely $(50,51)$. This approach, also named "Mobile Learning for Development", is the subject of recent studies concluding in the need for further research to better assess and adapt the approaches $(52,53)$. In Kenya, in a very similar manner to the Malakit intervention, an intervention included a WhatsApp group to strengthen "supervision, professional development and team building", and found also an interest in quality assurance, information sharing, and the creation of a supportive environment (54). More broadly, social interaction and peer assessment has been found to be associated with better guideline implementation and clinical practice change $(55,56)$. In the present project, the peer-to-peer form of supervision within the WhatsApp group was not observed. Facilitators of the two countries knew each other little or not at all due to few joint trainings or meetings (all of them needing visa to come to French Guiana). That is why they may not have felt comfortable enough to ask questions and share difficulties, and tended to rather share success. In-person peer supervision, at some point considered, which may be a mean to further foster performance, could not be implemented.

Although quite satisfactory after two years of intervention, coverage could be improved by a better planning of funds and resources for adapting to the gold miners' mobility in a timely manner, especially with an increasing heterogeneity of malaria transmission among gold mining regions. The findings underline the importance of the factors contributing to the trust of the population towards the project, especially with wary communities.

Research requirements namely, represent constraints regarding the perception of the community that should not be underestimated. Although still experimental, articulation with existing care services should have been further developed to avoid potential competition felt instead of complementarity. Nonetheless, the excellent appropriateness - as "perceived fit of the innovation to address a particular problem"- and good adoption from the study population are definitely not a barrier to the reach although it may become one with diminution of malaria prevalence (38). Maintaining community uptake may be achieved by expanding services offered by facilitators, as seen in Myanmar, where the management of non-malaria febrile illnesses and the referral of severely ill patients complemented "malaria only" CHW prerogatives (57). Participants acceptability and engagement were also very good despite the deterrent factor of time availability in some places (38).

\section{Conclusion}


These feedbacks reveal information that can improve the validity of the research project because the main results can now be interpreted in light of what was actually implemented (19). The satisfactory compliance with what was planned, the improvements to be done to reach the population and the good responsiveness of the participants are the main points observed. In addition, the confrontation of the protocol with reality highlights considerations that will be essential for the sustainability, applicability and transferability of the strategy in other contexts. $(58-60)$

\section{Declarations}

\section{Ethics approval and consent to participate}

The research study obtained all competent ethical approval required according to the respective regulations in

Brazil and Suriname. Written consent was obtained from all participants.

Ethical committee of the FUNDACAO OSWALDO CRUZ : CAAE: 89482118.0.0000.5248; Approval No: 2.831.534.

Ethical committee in Suriname for the Malakit study: CMWO. Approval No : VG 25-17.

Ethical committee in Suriname for the post intervention survey (short title: Orpal-2): CMWO. Approval No : DVG 738.

Ethical committee of the Univeristy of Montréal, "Comité d'éthique de la recherche- Société et culture (CER-SC)" for the qualitative study "Malakit Project: a complementary case study": Project CERSC-2019-083-D.

\section{Consent for publication}

"Not applicable"

\section{Availability of data and materials}

The datasets used and/or analysed during the current study are available from the corresponding author on reasonable request.

\section{Competing interests}

The authors declare that they have no competing interests

\section{Funding}

The $\mathrm{CHC}$, as sponsor, directly managed most of the project funds. Half of the funding was by the European Regional Development Fund (FEDER) via the Interregional Amazon Cooperation Program (IACP) $2014-2020$ (N Synergy 3949), supplemented with self-funding from the $\mathrm{CHC}$, funds from the French Guiana Health Regional Agency, the European Horizon 2020 Program and contributions in kind from the Surinamese Ministry of Health, as beneficiary of the GF (Global Fund to Fight AIDs, Tuberculosis and Malaria); the Ministry of Health of Brazil; 
the PAHO/WHO ECC (Pan-American Health Organization/World Health Organisation for Eastern Caribbean Countries) ; and the French Development Agency (Agence Française de Développement AFD).

The funding bodies have no role in the implementation and analysis of the project.

\section{Authors' contributions}

MSG, YL, LG, MSM, SV, MN, AA, HH, CP, AS and MD conceived the study and wrote the protocol. MSG, YL, LG, MSM, LM, SV, JBM, JHG, HC and MD implemented the study. MSG, LM, YL and MD performed the analysis. MSG, $\mathrm{YL}$ and MD wrote the first draft. All authors read and approved the final manuscript.

The authors confirm they had full access to the data in the study and accept responsibility to submit for publication.

\section{Acknowledgements}

The authors thank all facilitators from the Malakit Project. In Suriname: Breno Otavio Barbosa, Isadora Batista dos Santos, Astrid Huur, Carla Pereira de Paulo, Fernando Silva Rodrigues Barbosa, Nicholas Valente Ferreira. In Brazil: Samanta Braga, Salomao Brito, Alejandro Chavarro, André Da Silva Alancantara, Ronnie Edison and Leonardo Villalba-Bassulto.

Hélène Hilderal, Sam Trinh, Amandine Duclau, Nicolas Vigner and Cécile Longchamps (Hospital of Cayenne).

\section{References}

1. Blase K. Core Intervention Components: Identifying and Operationalizing What Makes Programs Work. 2013 [cited 2020 Sep 2]; Available from: https://calio.dspacedirect.org/handle/11212/1465

2. Implementation Research: A Synthesis of the Literature [Internet]. [cited 2020 Sep 2]. Available from: http://www.incredibleyears.com/article/implementation-research-a-synthesis-of-the-literature/

3. Cambon L, Minary L, Ridde V, Alla F. Transferability of interventions in health education: a review. BMC Public Health. 2012 Jul 2;12(1):497.

4. Moore GF, Audrey S, Barker M, Bond L, Bonell C, Hardeman W, et al. Process evaluation of complex interventions: Medical Research Council guidance. BMJ. 2015 Mar 19;350:h1258.

5. Evaluation designs for adequacy, plausibility and probability of public health programme performance and impact. - PubMed - NCBI [Internet]. [cited 2019 Mar 15]. Available from:

https://www.ncbi.nlm.nih.gov/pubmed/10195658

6. Mitchell O. Experimental Research Design. In: The Encyclopedia of Crime \& Punishment [Internet]. American Cancer Society; 2015 [cited 2021 May 21]. p. 1-6. Available from:

https://onlinelibrary.wiley.com/doi/abs/10.1002/9781118519639.wbecpx113

7. Hwang S, Birken SA, Melvin CL, Rohweder CL, Smith JD. Designs and methods for implementation research: Advancing the mission of the CTSA program. J Clin Transl Sci. 4(3):159-67. 
8. Tosh G, Soares-Weiser K, Adams CE. Pragmatic vs explanatory trials: the Pragmascope tool to help measure differences in protocols of mental health randomized controlled trials. Dialogues Clin Neurosci. 2011 Jun;13(2):209-15.

9. Patsopoulos NA. A pragmatic view on pragmatic trials. Dialogues Clin Neurosci. 2011 Jun;13(2):217-24.

10. Douine M, Lambert Y, Musset L, Hiwat H, Reis Blume L, Marchesini P, et al. Malaria in Gold Miners in the Guianas and the Amazon: Current Knowledge and Challenges (in press). Current Tropical Medicine Reports. 2020;

11. Heemskerk M, Duijves C. Study on the knowledge, attitudes and practices of malaria and malaria treatment in the small-scale gold mining sector in Suriname. [Internet]. Submitted to the US Agency for International Development by the Systems for Improved Access to Pharmaceuticals and Services (SIAPS) Program.; 2013. Available from: http://siapsprogram.org/publication/study-on-the-knowledge-attitudes-and-practices-ofmalaria-and-malaria-treatment-in-the-small-scale-gold-mining-sector-in-suriname/

12. Murta FLG, Marques LLG, Santos APC, Batista TSB, Mendes MO, Silva ED, et al. Perceptions about malaria among Brazilian gold miners in an Amazonian border area: perspectives for malaria elimination strategies. Malaria Journal. 2021 Jun 26;20(1):286.

13. Musset L, Pelleau S, Girod R, Ardillon V, Carvalho L, Dusfour I, et al. Malaria on the Guiana Shield: a review of the situation in French Guiana. Memorias do Instituto Oswaldo Cruz. 2014 Aug;109(5):525-33.

14. Douine M, Musset L, Corlin F, Pelleau S, Pasquier J, Mutricy L, et al. Prevalence of Plasmodium spp. in illegal gold miners in French Guiana in 2015: a hidden but critical malaria reservoir. Malar J. 2016;15:315.

15. Douine M, Sanna A, Galindo M, Musset L, Pommier de Santi V, Marchesini P, et al. Malakit: an innovative pilot project to self-diagnose and self-treat malaria among illegal gold miners in the Guiana Shield. Malaria Journal. 2018 Apr 10;17(1):N.PAG-N.PAG.

16. Douine M, Lazrek Y, Blanchet D, Pelleau S, Chanlin R, Corlin F, et al. Predictors of antimalarial self-medication in illegal gold miners in French Guiana: a pathway towards artemisinin resistance. J Antimicrob Chemother. 2018 Jan 1;73(1):231-9.

17. Galindo MS, Lambert Y, Mutricy L, Garancher L, Bordalo Miller J, Gomes JH, et al. Setting-up a cross-border action-research project to control malaria in remote areas of the Amazon: describing the birth and milestones of a complex international project (Malakit). Malaria Journal. 2021 May 11;20(1):216.

18. Nacher M, Guerin PJ, Demar-Pierre M, Djossou F, Nosten F, Carme B. Made in Europe: will artemisinin resistance emerge in French Guiana? Malaria journal. 2013;12:152.

19. Douine M, Lambert Y, Galindo M, Mutricy L, Sanna A, Peterka C, et al. Self-Diagnosis and Self-Treatment of Malaria in Hard-to-Reach and Mobile Populations of the Amazon: Results of Malakit, a Multicentric Intervention Research Project. Towards a Paradigm Shift? [Internet]. Rochester, NY: Social Science Research Network; 2021 [cited 2021 Jul 1]. Report No.: ID 3850058. Available from:

https://papers.ssrn.com/abstract=3850058

20. Parent A-A, Galindo MS, Lambert Y, Douine M. Maliqua: A study within Malakit, a project on malaria and gold miners in French Guiana. medRxiv. 2021 May 18;2021.05.16.21257287.

21. WHO Meeting on the Prevention of the Re-Introduction of Malaria (1966: Washington DC), Organization WH. Prevention of the re-introduction of malaria: report of a WHO meeting [held in Washington, D.C. from 14 to 18 November 1966] [Internet]. World Health Organization; 1967 [cited 2020 Nov 30]. Available from: https://apps.who.int/iris/handle/10665/40670

Page $17 / 24$ 
22. Wangdi K, Gatton ML, Kelly GC, Clements AC. Cross-border malaria: a major obstacle for malaria elimination. Advances in parasitology. 2015 Jun;89:79-107.

23. Guyant P, Corbel V, Guérin PJ, Lautissier A, Nosten F, Boyer S, et al. Past and new challenges for malaria control and elimination: the role of operational research for innovation in designing interventions. Malar $\mathrm{J}$ [Internet]. 2015 Jul 17 [cited 2021 Jan 22];14. Available from: https://www.ncbi.nlm.nih.gov/pmc/articles/PMC4504133/

24. Pongvongsa $T, H a ~ H$, Thanh $L$, Marchand RP, Nonaka $D$, Tojo $B$, et al. Joint malaria surveys lead towards improved cross-border cooperation between Savannakhet province, Laos and Quang Tri province, Vietnam. Malar J. 2012 Aug 3;11:262.

25. Gordon A, Vander Meulen RJ, Maglior A. The 2019 Isdell:Flowers Cross Border Malaria Initiative Round Table: community engagement in the context of malaria elimination. Malaria Journal. 2019 Dec 19;18(1):432.

26. Asia WHORO for S-E. Meeting on cross border collaboration on malaria elimination along the India- Bhutan border. 4-5 Nov 2019, Guwahati, Assam, India. 2020 [cited 2020 Dec 1]; Available from: https://apps.who.int/iris/handle/10665/331933

27. Castellanos A, Chaparro-Narváez P, Morales-Plaza CD, Alzate A, Padilla J, Arévalo M, et al. Malaria in goldmining areas in Colombia. Memórias do Instituto Oswaldo Cruz. 2016 Jan;111(1):59-66.

28. Aché A, Escorihuela M, Vivas E, Páez E, Miranda L, Matos A, et al. In vivo drug resistance of falciparum malaria in mining areas of Venezuela. Trop Med Int Health. 2002 Sep;7(9):737-43.

29. Lyttleton C. Deviance and resistance: Malaria elimination in the greater Mekong subregion. Soc Sci Med. 2016 Feb;150:144-52.

30. Yan S, Orkis J, Sohail S, Wilson S, Davis T, Storey J. Digging for care-seeking behaviour among gold miners in the Guyana hinterland: a qualitative doer non-doer analysis of social and behavioural motivations for malaria testing and treatment. Malaria Journal. 2020 Jul 6;19.

31. Hoffmann TC, Glasziou PP, Boutron I, Milne R, Perera R, Moher D, et al. Better reporting of interventions: template for intervention description and replication (TIDieR) checklist and guide. BMJ. 2014 Mar 7;348:g1687.

32. Schloemer T, Schröder-Bäck P. Criteria for evaluating transferability of health interventions: a systematic review and thematic synthesis. Implementation Science. 2018 Jun 26;13(1):88.

33. Remme JHF, Adam T, Becerra-Posada F, D’Arcangues C, Devlin M, Gardner C, et al. Defining Research to Improve Health Systems. PLoS Med [Internet]. 2010 Nov 16 [cited 2021 Apr 22];7(11). Available from: https://www.ncbi.nlm.nih.gov/pmc/articles/PMC2993153/

34. Peters DH, Adam T, Alonge O, Agyepong IA, Tran N. Republished research: Implementation research: what it is and how to do it: Implementation research is a growing but not well understood field of health research that can contribute to more effective public health and clinical policies and programmes. This article provides a broad definition of implementation research and outlines key principles for how to do it. Br J Sports Med. 2014 Apr;48(8):731-6.

35. Curran GM, Bauer M, Mittman B, Pyne JM, Stetler C. Effectiveness-implementation Hybrid Designs. Med Care. 2012 Mar;50(3):217-26.

36. Landes SJ, McBain SA, Curran GM. An introduction to effectiveness-implementation hybrid designs. Psychiatry Research. 2019 Oct 1;280:112513. 
37. Carroll C, Patterson M, Wood S, Booth A, Rick J, Balain S. A conceptual framework for implementation fidelity. Implementation Science. 2007 Nov 30;2(1):40.

38. Proctor E, Silmere H, Raghavan R, Hovmand P, Aarons G, Bunger A, et al. Outcomes for implementation research: conceptual distinctions, measurement challenges, and research agenda. Adm Policy Ment Health. 2011 Mar;38(2):65-76.

39. Landier J, Parker DM, Thu AM, Carrara VI, Lwin KM, Bonnington CA, et al. The role of early detection and treatment in malaria elimination. Malaria Journal. 2016 Jul 15;15(1):363.

40. Landier J, Parker DM, Thu AM, Lwin KM, Delmas G, Nosten FH, et al. Effect of generalised access to early diagnosis and treatment and targeted mass drug administration on Plasmodium falciparum malaria in Eastern Myanmar: an observational study of a regional elimination programme. The Lancet. 2018 May 12;391(10133):1916-26.

41. World Health Organization. Guidelines for the treatment of malaria. Third edition. 2015.

42. Tailoring Mobile Data Collection for Intervention Research in a Challenging Context: Development and Implementation in the Malakit Study [Internet]. JMIR Preprints. [cited 2021 May 31]. Available from: https://preprints.jmir.org/preprint/29856

43. Lehmann U, Sanders D. Policy Brief: Community Health Workers: What Do We Know About Them? The State of the Evidence on Programmes, Activities, Costs and Impact on Health Outcomes of Using Community Health Workers. WHO, Evidence and Information for Policy. 2007 Jan 1;2.

44. Videos [Internet]. Malakit. [cited 2020 Nov 20]. Available from: https://www.malakit-project.org/videos/

45. Galindo M, Lambert Y, Mutricy L, Garancher L, Miller J, Gomes J, et al. Setting-Up A Cross-Border ActionResearch Project to Control Malaria in Remote Areas of the Amazon: Describing the Birth and Milestones of $A$ Complex International Project (Malakit). 2020.

46. Mendel P, Meredith LS, Schoenbaum M, Sherbourne CD, Wells KB. Interventions in Organizational and Community Context: A Framework for Building Evidence on Dissemination and Implementation in Health Services Research. Adm Policy Ment Health. 2008 Mar;35(1-2):21-37.

47. Dane AV, Schneider BH. PROGRAM INTEGRITY IN PRIMARY AND EARLY SECONDARY PREVENTION: ARE IMPLEMENTATION EFFECTS OUT OF CONTROL? Clinical Psychology Review. 1998 Jan 1;18(1):23-45.

48. Adeoti O, Spiegelman D, Afonne C, Falade CO, Jegede AS, Oshiname FO, et al. The fidelity of implementation of recommended care for children with malaria by community health workers in Nigeria. Implementation Science. 2020 Mar 4;15(1):13.

49. O'Donovan J, O’Donovan C, Kuhn I, Sachs SE, Winters N. Ongoing training of community health workers in low-income and middle-income countries: a systematic scoping review of the literature. BMJ Open. 2018 Apr $1 ; 8(4): e 021467$.

50. Braun R, Catalani C, Wimbush J, Israelski D. Community Health Workers and Mobile Technology: A Systematic Review of the Literature. PLOS ONE. 2013 Jun 12;8(6):e65772.

51. Yadav D. Low-Cost Mobile Learning Solutions for Community Health Workers. In: Proceedings of the 26th International Conference on World Wide Web Companion [Internet]. Republic and Canton of Geneva, CHE: International World Wide Web Conferences Steering Committee; 2017 [cited 2021 Jan 22]. p. 729-34. (WWW '17 Companion). Available from: https://doi.org/10.1145/3041021.3053377

52. Feroz A, Jabeen R, Saleem S. Using mobile phones to improve community health workers performance in low-and-middle-income countries. BMC Public Health. 2020 Jan 13;20(1):49. 
53. Winters N, Langer L, Nduku P, Robson J, O’Donovan J, Maulik P, et al. Using mobile technologies to support the training of community health workers in low-income and middle-income countries: mapping the evidence. BMJ Global Health. 2019 Jul 1;4(4):e001421.

54. Henry JV, Winters N, Lakati A, Oliver M, Geniets A, Mbae SM, et al. Enhancing the Supervision of Community Health Workers With WhatsApp Mobile Messaging: Qualitative Findings From 2 Low-Resource Settings in Kenya. Glob Health Sci Pract. 2016 Jun 20;4(2):311-25.

55. Grol R. Personal paper. Beliefs and evidence in changing clinical practice. BMJ. 1997 Aug 16;315(7105):418-21.

56. Maas MJM, van der Wees PJ, Braam C, Koetsenruijter J, Heerkens YF, van der Vleuten CPM, et al. An Innovative Peer Assessment Approach to Enhance Guideline Adherence in Physical Therapy: Single-Masked, Cluster-Randomized Controlled Trial. Physical Therapy. 2015 Apr 1;95(4):600-12.

57. McLean ARD, Wai HP, Thu AM, Khant ZS, Indrasuta C, Ashley EA, et al. Malaria elimination in remote communities requires integration of malaria control activities into general health care: an observational study and interrupted time series analysis in Myanmar. BMC Med. 2018 Oct 22;16:183.

58. Mukanga D, Babirye R, Peterson S, Pariyo GW, Ojiambo G, Tibenderana JK, et al. Can lay community health workers be trained to use diagnostics to distinguish and treat malaria and pneumonia in children? Lessons from rural Uganda. Trop Med Int Health. 2011 Oct;16(10):1234-42.

59. Hawkes M, Katsuva JP, Masumbuko CK. Use and limitations of malaria rapid diagnostic testing by community health workers in war-torn Democratic Republic of Congo. Malaria Journal. 2009 Dec 23;8(1):308.

60. Counihan H, Harvey SA, Sekeseke-Chinyama M, Hamainza B, Banda R, Malambo T, et al. Community health workers use malaria rapid diagnostic tests (RDTs) safely and accurately: results of a longitudinal study in Zambia. Am J Trop Med Hyg. 2012 Jul;87(1):57-63.

\section{Figures}




\begin{tabular}{|c|c|c|c|c|c|c|}
\hline Problems & $\begin{array}{c}\text { Evidence } \\
\text { base }\end{array}$ & $\begin{array}{l}\text { Inputs/ } \\
\text { Resources }\end{array}$ & $\begin{array}{c}\text { Processes } B_{k} \\
\text { Actions }\end{array}$ & Short-term & $\begin{array}{l}\text { Outcomes-Imp } \\
\text { Mid-term }\end{array}$ & Long-term \\
\hline $\begin{array}{l}\text { Living and working } \\
\text { conditions favorable } \\
\text { to vector } \\
\text { transmission [11-12] } \\
\text { Population } \\
\text { Mobility [10] } \\
\text { Low access to } \\
\text { health care: } \\
\text { remoteness, illegal } \\
\text { status, cost etc. } \\
\text { [10,14] } \\
\text { High access to black } \\
\text { market medicine } \\
\text { [11,16,18] } \\
\text { No access to } \\
\text { diagnosis in mining } \\
\text { sites [18] } \\
\text { Bad treatment } \\
\text { adherence [10,14] } \\
\text { Little knowledge } \\
\text { about malaria, its } \\
\text { prevention and } \\
\text { treatment [16] } \\
\text { No possibility to } \\
\text { provide health care } \\
\text { on the goldmining } \\
\text { sites [10,16,15,18] }\end{array}$ & $\begin{array}{l}\text { Early management } \\
\text { after malaria } \\
\text { symptoms onset } \\
\text { with appropriate } \\
\text { medication with } \\
\text { good adherence: } \\
\text { TTreatment success } \\
\downarrow \text { Transmission } \\
\downarrow \text { Resistance risk } \\
\text { [39-41] } \\
\text { Treatment } \\
\text { compliance is better } \\
\text { when issued from a } \\
\text { health professional } \\
\text { than in case of self- } \\
\text { medication without } \\
\text { diagnosis [16] } \\
\text { Laypersons and } \\
\text { persons with poor } \\
\text { education can } \\
\text { perform RDT on } \\
\text { others after being } \\
\text { trained [ } 58-60 \text { ] }\end{array}$ & $\begin{array}{l}\text { Diverse funding: } \\
\text { from countries } \\
\text { involved, European } \\
\text { funds, international } \\
\text { funds } \\
\text { Institutional, } \\
\text { technical and } \\
\text { scientific support } \\
\text { Multi-disciplinary } \\
\text { team } \\
\text { Coordinators and } \\
\text { supervisors } \\
\text { Facilitators } \\
\text { belonging to the } \\
\text { gold mining } \\
\text { community } \\
\text { Premises } \\
\text { External services } \\
\text { providing }\end{array}$ & $\begin{array}{l}\text { Feasibility study for } \\
\text { self-test on-site } \\
\text { Frequent } \\
\text { International } \\
\text { meetings } \\
\text { Participatory } \\
\text { approach in } \\
\text { designing strategy } \\
\text { and materials } \\
\text { Prior and ongoing } \\
\text { training of } \\
\text { facilitators } \\
\text { Self-care kits } \\
\text { distribution or } \\
\text { replacement/ } \\
\text { replenishment to } \\
\text { participants, along } \\
\text { with training and } \\
\text { information by } \\
\text { facilitators } \\
\text { LLIN distribution } \\
\text { Smartphone app } \\
\text { presentation and } \\
\text { sharing } \\
\text { Supervision of } \\
\text { facilitators' work }\end{array}$ & $\begin{array}{l}\uparrow \text { Awareness of the } \\
\text { disease in the } \\
\text { population } \\
\uparrow \text { Knowledge of the } \\
\text { population about } \\
\text { the disease } \\
\uparrow \text { Skills of the } \\
\text { participants } \\
\uparrow \text { Access to } \\
\text { diagnosis } \\
\uparrow \text { Access to "first- } \\
\text { aid" treatment } \\
\uparrow \text { Access to LLINs } \\
\uparrow \text { Detection of cases } \\
\text { (through referrals to } \\
\text { malaria care } \\
\text { system) }\end{array}$ & $\begin{array}{l}\downarrow \text { Resort to black } \\
\text { market medicines } \\
\uparrow \text { Treatment } \\
\text { adherence } \\
\uparrow \text { LLIN use } \\
\downarrow \text { Transmission } \\
\text { among the } \\
\text { community and } \\
\text { populations in } \\
\text { contact (militaries, } \\
\text { autochthonous } \\
\text { population etc.) }\end{array}$ & $\begin{array}{l}\downarrow \text { Morbi-mortality } \\
\text { of the study } \\
\text { population } \\
\downarrow \text { Prevalence of } \\
\text { malaria in the study } \\
\text { population } \\
\text { AND } \\
\downarrow \text { Overall incidence } \\
\text { of malaria }\end{array}$ \\
\hline
\end{tabular}

\section{Figure 1}

Logic model of the Malakit intervention before the start of the Malakit study
French Guiana border
French Guiana forest
MINING SITES
DISTRIBUTION SITE

\section{French Guiana border \\ DISTRIBUTION SITE}

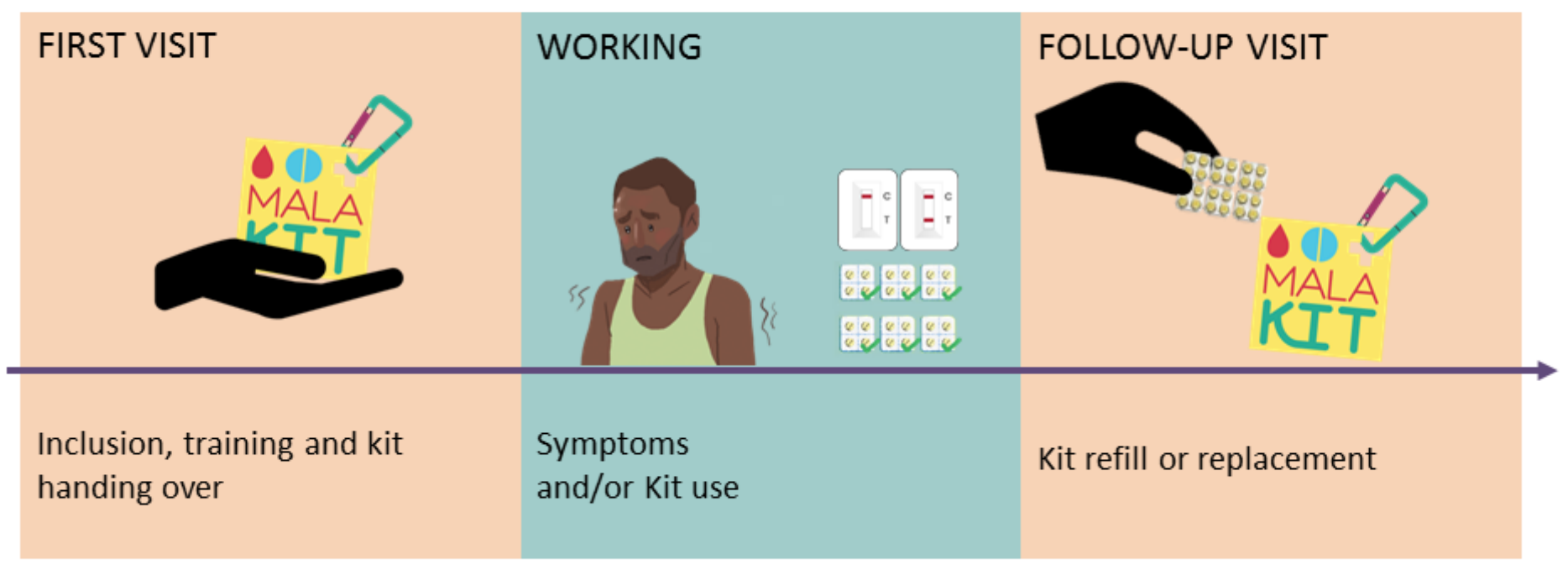




\section{Figure 2}

Principle of the Malakit intervention in Suriname and Brazil (April 2018-March 2020)
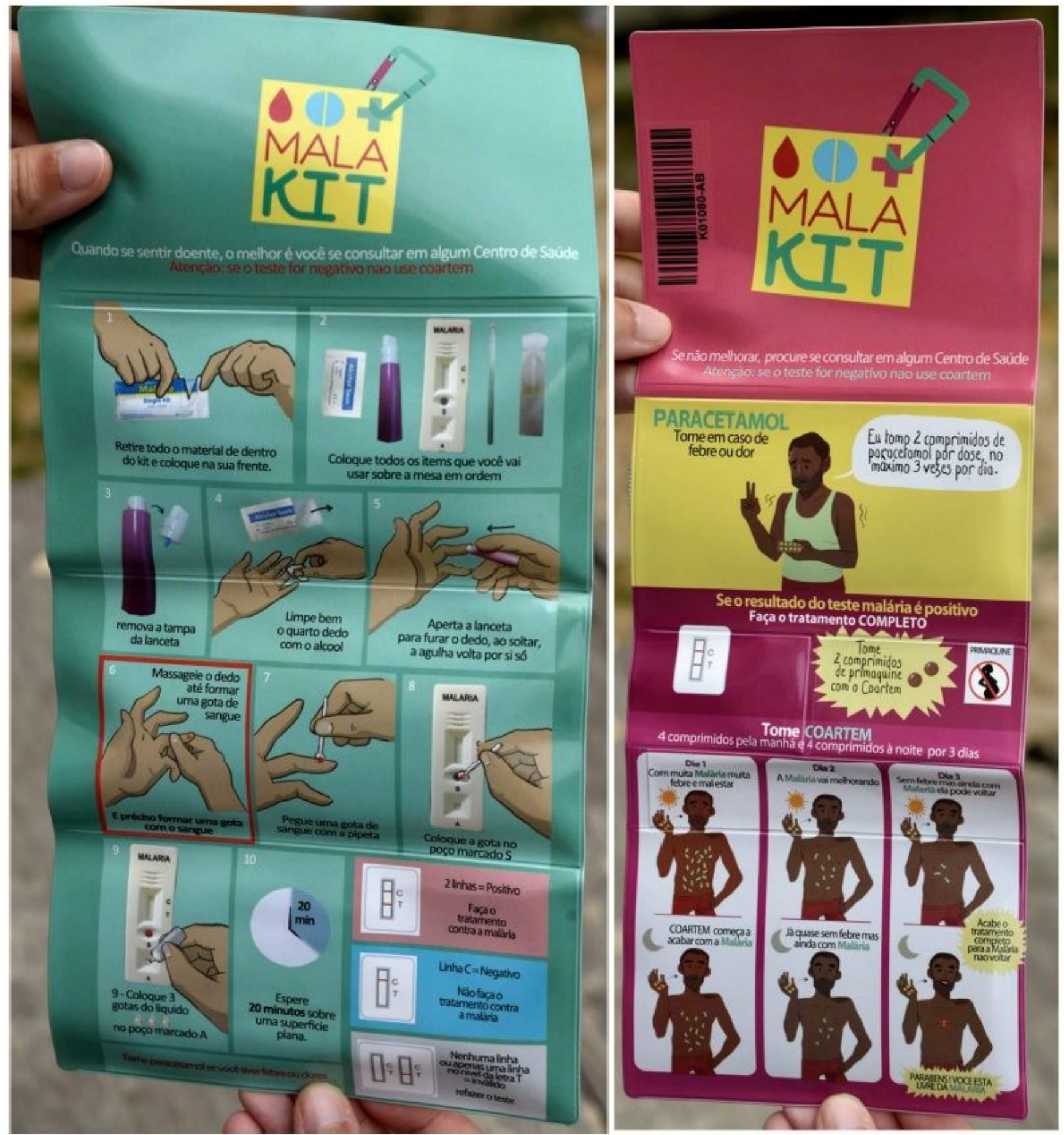

\section{Figure 3}

Illustrated instructions printed on the kits distributed during the Malakit study in Suriname and Brazil 


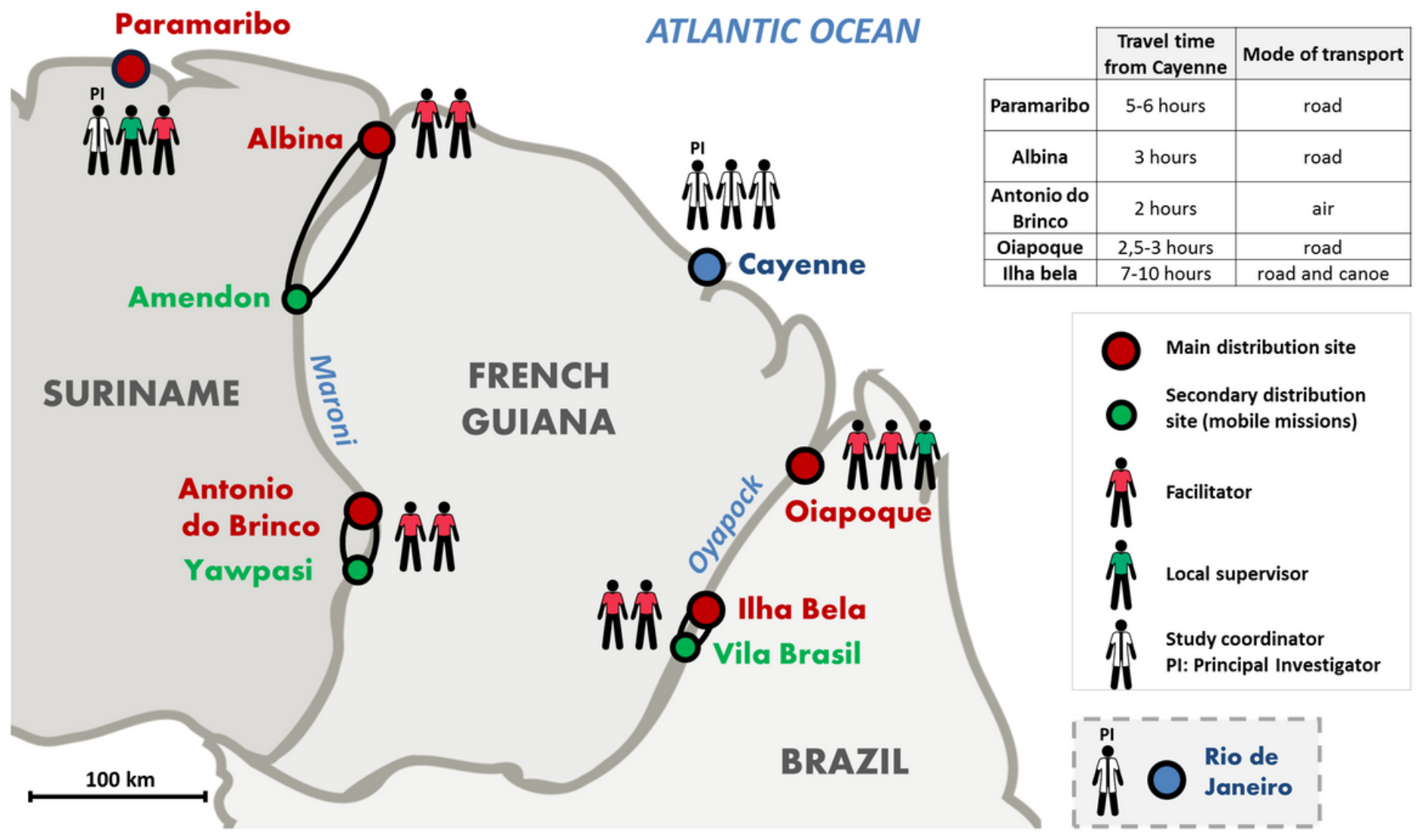

Figure 4

Map of the distribution sites of the Malakit intervention in Suriname and Brazil (April 2018-March 2020) 

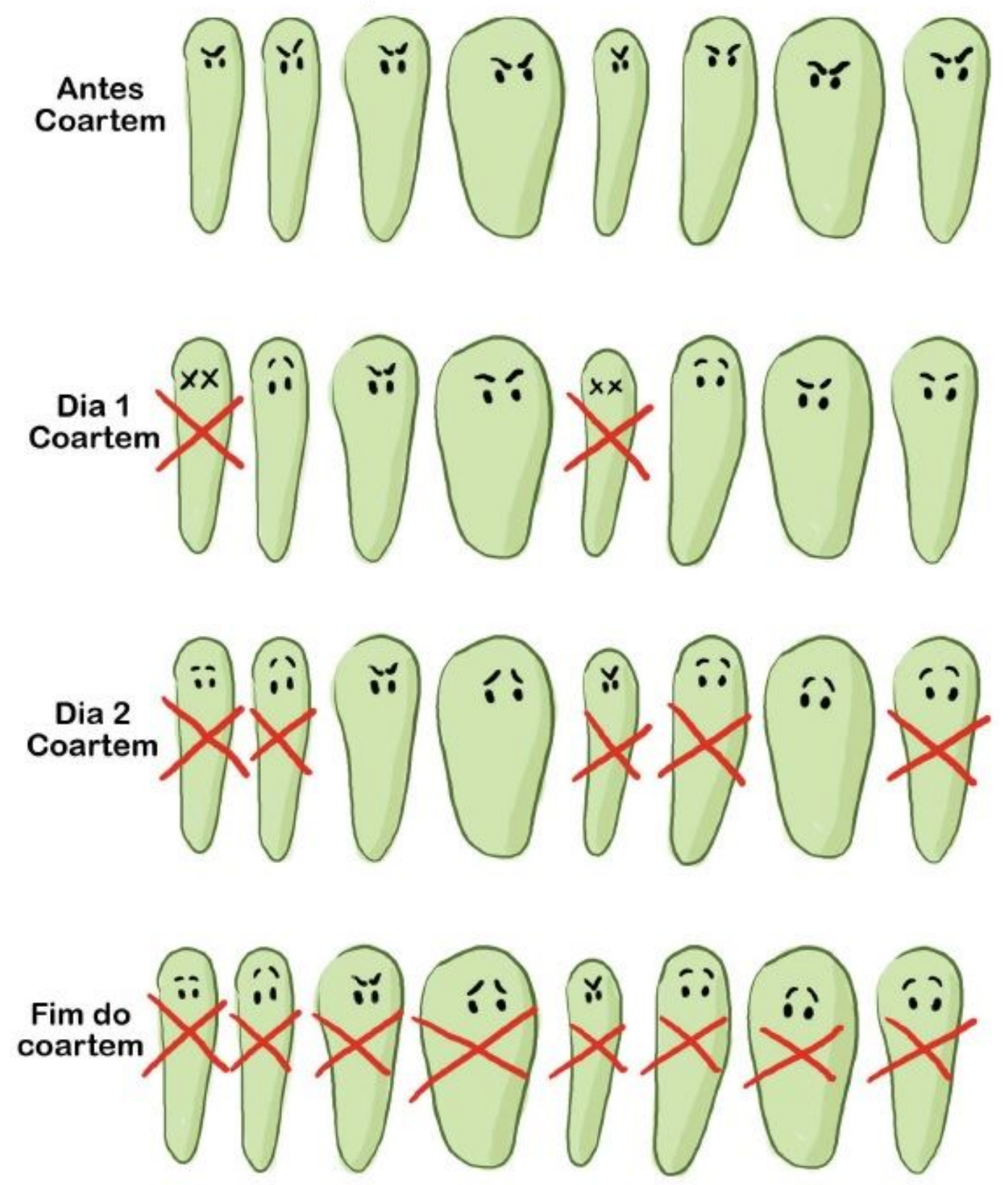

Figure 5

Poster illustrating the effect of the ACT on the malaria over time and the mechanism of resistance, material used during the training of participants of the Malakit intervention in Suriname and Brazil (April 2018-March 2020)

\section{Supplementary Files}

This is a list of supplementary files associated with this preprint. Click to download.

- Additionalfile1.docx

- Additionalfile2TIDieRChecklist.docx 